\title{
Correction to: Effects of I- and W-Phases Under Identical Conditions on Microstructure and Mechanical Properties of As-Cast Mg-Zn-Y Alloys at Room and Elevated Temperatures
}

\author{
Young-Gil Jung ${ }^{1} \cdot$ Wonseok Yang ${ }^{1} \cdot$ Jae Ik Hyun ${ }^{2} \cdot$ Shae K. Kim ${ }^{1} \cdot$ Hyunkyu Lim ${ }^{1}$ • Do Hyang Kim ${ }^{2}$
}

Published online: 9 December 2021

(c) The Korean Institute of Metals and Materials 2021

\section{Correction to: Metals and Materials International https://doi.org/10.1007/s12540-020-00848-w}

In the original publication of the article the Acknowledgements section was missing and the Acknowledgements section is given in this correction.

\section{Acknowledgements}

This work was supported by the Core Technology Development Program for Electronic Systems Industry (Project No. 20010917) funded by the Ministry of Trade, Industry \& Energy (MOTIE, Korea).

Publisher's Note Springer Nature remains neutral with regard to jurisdictional claims in published maps and institutional affiliations.

The original article can be found online at https://doi.org/10.1007/ s12540-020-00848-w.

Hyunkyu Lim

hklim@kitech.re.kr

Young-Gil Jung

jyg3602@kitech.re.kr

Wonseok Yang sonicyg@kitech.re.kr

Jae Ik Hyun

dfred1458@naver.com

Shae K. Kim

shae@kitech.re.kr

Do Hyang Kim

dohkim@yonsei.ac.kr

1 Advanced Materials and Process R\&D Department,

Korea Institute of Industrial Technology, Incheon 21999,

Republic of Korea

2 Department of Metallurgical Engineering, Yonsei University, Seoul 03722, Republic of Korea 